\title{
'Healthier Fleetwood': Creating healthier communities via improved social networking in a disadvantaged area of the UK
}

\author{
MARK SPENCER
}

\begin{abstract}
Reducing the prevalence of diabetes and other non-communicable diseases is an urgent clinical priority for the UK and other countries. Achieving improved social networking among isolated people with long-term health needs has been shown to build confidence and self-efficacy, leading to improved health and other outcomes, improved service delivery and to reduce healthcare costs. This article describes the 'Healthier Fleetwood' initiative which uses social networking to increase physical activity and improve diet, which are key to preventing the onset of diabetes and other noncommunicable diseases.
\end{abstract}

Br J Diabetes 2017;17:ONLINE AHEAD OF PUBLICATION

Key words: social networking, prevention, contact, control, confidence, healthier lives.

\section{Introduction}

Reducing the prevalence of diabetes and other non-communicable diseases (NCDs) is an urgent clinical priority for the UK and other countries. Local initiatives based firmly within the culture of local communities are valuable approaches to achieve this goal. 'Healthier Fleetwood' is a programme based in an area of widespread social disadvantage in the north of England. The programme is based on the potential of fostering social networking, which has been shown to build confidence and self-efficacy, and to empower local communities to bring about positive change. Approaches based on improved social networking have been shown previously in other areas to improve health and other outcomes, to improve service delivery and to reduce healthcare costs.

'Healthier Fleetwood' is a programme designed to promote social interaction and to increase physical activity using established local initiatives, such as shared management of green spaces. Engagement with schoolchildren and families is planned to improve knowledge regarding a healthier diet.

The Mountain View Practice, Fleetwood Health and Wellbeing Centre, Fleetwood, UK

Address for correspondence: $\operatorname{Dr}$ Mark Spencer

The Mountain View Practice, Fleetwood Health and Wellbeing Centre, Dock Street, Fleetwood, FY7 6HP, UK

E-mail: mark.spencer1@nhs.net

http://dx.doi.org/10.15277/bjd.2017.138
Figure 1. Social disadvantage in Fleetwood: quintiles of deprivation score compared with the UK national average

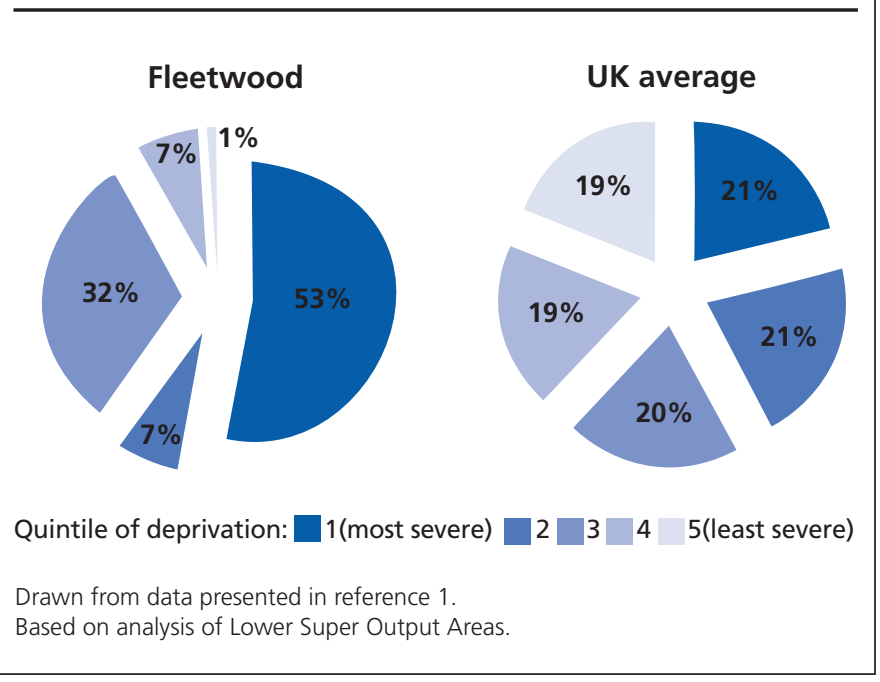

\section{Social and clinical context: Fleetwood}

Demographic and disease characteristics from Fleetwood have been compiled by Lancashire County Council: their findings, summarised briefly here, describe an area of substantial disadvantage and unmet healthcare needs. ${ }^{1}$ Fleetwood is situated on the Fylde coast in Lancashire, with a population of about 25,000 (98\% white/ Caucasian, evenly balanced between genders). Families with needs and low income workers were two of the three dominant social groups identified by Mosaic demographic analysis.

About half of individuals registered at local primary care practices (including ours) were in the lowest (most severe) category of socioeconomic disadvantage compared with about one-fifth for the national UK average (Figure 1). Similarly, the proportions in the highest (least severe) quintile for social disadvantage were markedly lower for Fleetwood compared with the UK as a whole (Figure 1). Five local government wards containing $93 \%$ of the local population rank between 6,127 and 7,552 for a social deprivation index, out of 7,632 such areas in the UK. The prevalence of $18 / 20$ specific ailments is higher than the national UK average in Fleetwood, including diabetes (7.9\% vs. $6.4 \%)$. Life expectancy varies greatly across the region, from 9-10 years lower life expectancy than the UK average in one ward to 8 years higher than the national average in another, with similar trends for men and women. 


\section{Background to the intervention}

The principal objective of the intervention is to encourage residents of Fleetwood to improve their lifestyles. Healthcare professionals will doubtless be familiar with the negative (or frankly sceptical2) response to a need for lifestyle modification among sedentary, obese patients who would likely benefit from it the most. The author's personal experience includes too many patients who are unable to see beyond the pressing concerns of getting through each day to engage constructively with their need for an improved lifestyle. Accordingly, 'Healthier Fleetwood' draws on a model of 'Health Creation' within a context of improved social networks. ${ }^{3}$ This approach helps to empower patients to take greater responsibility for their healthcare needs by giving them a greater feeling of engagement with, and control of, their environment. 'Contact', 'Confidence' and 'Control', as described below.

\section{Importance of social networks: contact, confidence, control}

\section{Long-term health}

Participation within social networks - contact with friends, relations, acquaintances, colleagues, etc - has been associated strongly with positive health and other outcomes ${ }^{4}$ (see Figure 2 ). Benefits associated with access to a social network include reduced risk of depression ${ }^{5}$ and better maintenance of cognitive function (and reduced risk of dementia) in older persons. ${ }^{6,7}$ Conversely, the absence of social networks is associated with negative health outcomes.8,9 Greater versus lesser participation in social networks was associated with reduced mortality in a large meta-analysis (308,849 subjects

Figure 2. Importance of concepts of contact, confidence and control in building social networks to promote improved local health or other outcomes

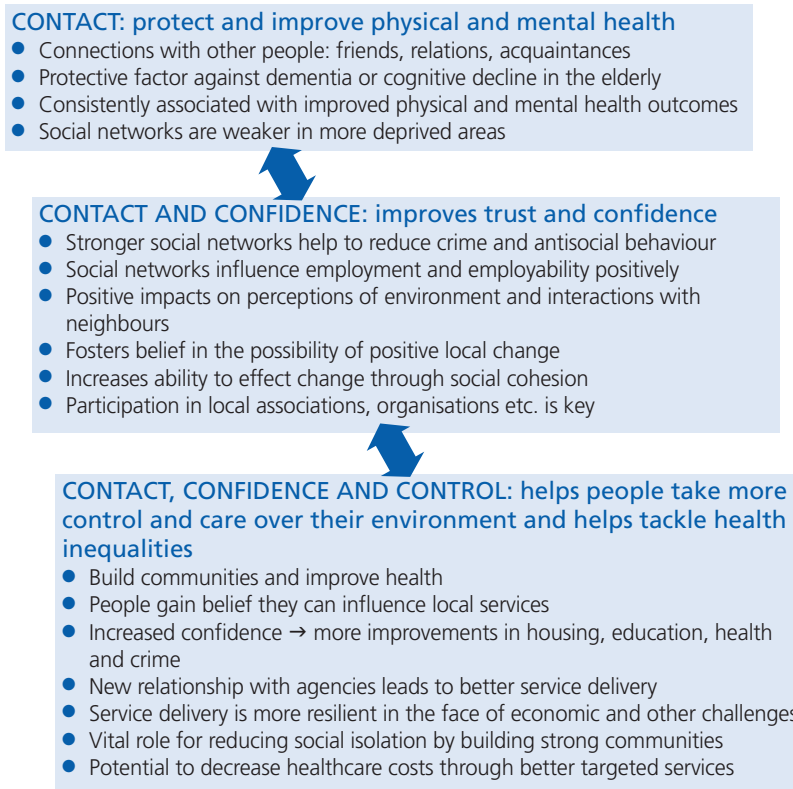

See text for supporting evidence and references across 148 studies), particularly when a complex measure of social integration was used that reflected the multifaceted needs of the study population (odds ratio $1.91,95 \% \mathrm{Cl} 1.63$ to 2.23). ${ }^{10}$

These findings are consistent with a need to shift the focus of care for NCDs such as diabetes from a medical to a non-medical societal model to engage communities better in their own healthcare creation, facilitated by better contact and support from local stakeholders in healthcare and local and national government. ${ }^{3}$ Interventions based in the community provide opportunities to improve social networking. A community-based public health intervention in Lewisham, London (another area with high levels of disadvantage), designed with strong links with general practice, confirms the potential benefits from this approach. ${ }^{11}$ The intervention resulted in increased numbers of local residents entering a smoking cessation support service (up to $62 \%$ by area), more fruit and vegetables consumed by $22 \%$ and $33 \%$ increased their physical activity; overall, 53\% reported positive lifestyle changes.

\section{Other social benefits}

Areas with stronger social networks (higher 'collective efficacy'12) experience less crime and delinquency, and the formation of social ties increases the confidence of residents in their community by promoting social organisation. ${ }^{13,14}$ Additionally, promoting social networks facilitates employment and enhances employability, ${ }^{15}$ while helping to build an environment with lower levels of crime and antisocial behaviours. The Healthy Communities Collaborative, a community-driven initiative led by local people which promoted social cohesion and teamwork, demonstrated increases in perceptions of the area being a good place to live (12\%); the extent to which people showed concern for each other (12\%); and belief in the possibility of effecting positive change in their community (48\%). ${ }^{16}$ Social cohesion and informal social control are key to bringing a community together to improve its environment; crucially, the main success factor in such an approach is participation in local organisations, associations, clubs, etc. ${ }^{17}$

In the UK, a community development programme on the Beacon estate in Cornwall demonstrated significant and sustained changes, defined and designed by the community themselves. ${ }^{3}$ Working together fostered belief in their ability to effect change, building confidence to secure improvements in housing, education, health and crime, and these benefits were sustained for 15 years by $2014 .^{3}$ Ability to exert control is an important facet of the psychosocial environment, and this has been described as an important risk factor for coronary heart disease related to stressful employment. ${ }^{18}$ Elsewhere, the 'LinkAge Plus' programme developed and deepened social networks for older people while redesigning services with their help, resulting in significant improvements in health and independence. ${ }^{19}$

\section{Better public services}

Supporting people to take greater control of their environment, as seen for example in the project in Lewisham described above, in turn facilitates negotiation of new relationships with statutory agencies, saving time and resources for local government, with the potential for improved and more effectively delivered services. ${ }^{20,21}$ 
Involvement of the state and its services are critical to enabling control and independence, with local activity in a national context appearing to be especially effective. ${ }^{22}$ In addition, this approach helps to build resilience into public services, in the face of economic or other challenges. ${ }^{23}$

\section{Cost-effectiveness}

Investment to address the association between poor health and poor social networks can both break the cycle of disadvantage and also decrease the cost of healthcare. ${ }^{24}$ Experience from the NHSfunded Health Empowerment Leverage Project (HELP), based on the process of asset-based community development, suggests achievable savings of about $£ 80,000 /$ year/neighbourhood. ${ }^{25}$ The same author suggests that two years of work should leave a selfrenewing resident group, supported by existing front-line workers, supported by the longevity of the Beacon project described above. An internal analysis from HELP26 suggested a 3-year saving to the NHS of $f 558,714$ across three neighbourhoods based on 'cautious but evidence-based' estimates of $5 \%$ improvements in health factors resulting from increased community activity and building social networks. This represented a return of 1:3.8 on a $£ 145,000$ investment in community development, with additional savings of f96,448/year/neighbourhood from reduced crime and antisocial behaviour. Other data support these findings. ${ }^{27}$

Building social networks reduces NHS service use. Supporting social networks for people with coronary heart disease and diabetes led to significant reductions in NHS service use in a longitudinal study. ${ }^{28}$ The UK government-funded Partnerships for Older People Project with older people included a range of social provisions, from lunch clubs to formal services to aid discharge from hospital. ${ }^{29}$ Overall, the programme achieved reductions in overnight hospital stays (by $47 \%$ ), use of emergency department visits (by 29\%), telephone calls to GPs (by 28\%) and GP appointments (by 10\%). Each $f 1$ spent on these services generated $\mathrm{f} 1.20$ in savings on emergency inpatient provision. The National Endowment for Science Technology and the Arts (NESTA) estimated that 'people powered health interventions' can reduce emergency department visits, planned/unplanned hospital admissions and the need for outpatient services.30 NESTA calculated the potential savings to be $7 \%$ overall for Clinical Commissioning Groups (CCGs; average of $\mathrm{f} 21$ million/CCG) and £4.4 billion across all of England. ${ }^{30}$

\section{Building social networks in Fleetwood}

GPs in the area can prescribe gym-based exercise via the Y-Active Project run by our local YMCA. ${ }^{31}$ However, many people do not enjoy - and thus do not adhere to - this type of intervention. 'Healthier Fleetwood' builds on existing local activities to promote improved diet and increased physical activity within enhanced social networks. For example, the Willow Garden Project has been used as an inspiration to create more green spaces locally, maintained by volunteers to look after them..$^{32}$ The positive effect on the local environment helps further to build community cohesion, within a virtuous cycle. A dedicated Dementia Garden will feature healthpromoting herbs and vegetation, as well as 'reminiscence spaces'.

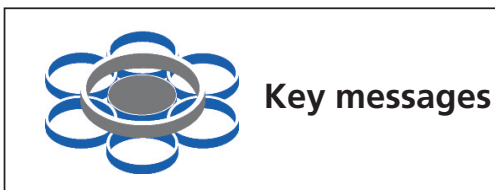

- Reducing the prevalence of non-communicable diseases including diabetes is an urgent clinical priority

- Pragmatically designed local initiatives will play an important part in national health promotion strategies

- 'Healthier Fleetwood' is a programme aimed at improving social networking for isolated individuals in poor health

- Improved social networking has been shown to build confidence and self-efficacy, empower local communities to bring about positive change, better healthcare delivery, improved health and other outcomes and reduced healthcare costs

- 'Healthier Fleetwood' uses established local initiatives to foster social networking, increased physical activity and improved food choices

Our volunteer gardeners will also tend to the gardens of the elderly who are no longer able to look after them themselves. Again this will not only have positive physical benefits but it will also reduce the degree of social isolation experienced by the elderly and housebound. These activities are consistent with the twin aims of increasing social interaction and increasing physical activity. We will also focus on increasing activity levels amongst primary school-aged children via a number of initiatives, such as running a daily mile.

Improved diet is another area of focus. Social groupings create an opportunity to move away from processed foods towards teaching people to eat more healthily. Fleetwood is historically a fishing community, providing an opportunity to focus on the benefits of this source of lean protein. Moreover, parents and children have lost the social interaction of cooking and eating together. We plan to bring an educator into our primary schools and then have them cook for their parents, and then sit and enjoy the meal together using the facilities of local restaurants and Fleetwood Town Football Club, another notable local social institution.

\section{Discussion}

Good adherence with lifestyle interventions, with associated weight loss, holds the key to reducing the risk of NCDs, including diabetes, in at-risk populations. ${ }^{33} \mathrm{~A}$ systematic review confirmed that diabetes prevention programmes with a pragmatic design suited to realworld situations can deliver worthwhile weight loss and reduced risk of diabetes. ${ }^{34}$ However, the proportion of individuals who successfully increase their level of physical activity and improve their diet over the long term is usually low, not least because they do not understand and/or believe in the potential benefits to be gained from an improved lifestyle. ${ }^{2}$

Reducing social isolation by building strong communities appears to be a key component of approaches to tackling health 
inequalities at a community level. ${ }^{22}$ The evidence described above suggests that a combination of self-help and independence with peer support, social inclusion, availability of meaningful groupbased activities, advocacy and support that is responsive, personalised and dependable will reduce the detrimental health impact of long-term conditions such as diabetes. Small simple interventions designed by local people have had significant beneficial effects. Such an approach appears to be suited ideally to the development of local activities at a time when diabetes prevention is identified as a significant national health priority. 'Healthier Fleetwood' is designed to build on the established theoretical promise of social networking, with activities designed pragmatically and firmly embedded within the customs and culture of the local community.

Acknowledgements The author wishes to thank Karen Boylan and all involved with Healthier Fleetwood, and Hazel Stuteley and the Connecting Communities Team at Exeter University. Dr Mike Gwilt (GT Communications) provided editorial assistance (free of charge) in the development of this article. A BBC blog written by the author has previously provided a brief account of this project for the BBC website. ${ }^{35}$

\section{Conflict of interest None. \\ Funding None.}

\section{References}

All websites accessed Jan 2017

1. Lancashire County Council, Fylde coast health economy neighbourhood profiles. Fleetwood neighbourhood. http://www.lancashire.gov.uk/media/ 898094/fleetwood-neighbourhood.pdf

2. Strain $W D, \cos X$, Hirst $M$, et al. Time to do more: addressing clinical inertia in the management of type 2 diabetes mellitus. Diabetes Res Clin Pract 2014;105:302-12. http://dx.doi.org/10.1016/j.diabres.2014.05.005

3. Fisher B, Lewith $G$, Falkenberg T, Jonas WB. Fostering health creation: community development to address long-term conditions. Glob Adv Health Med 2014;3:29-36. http://dx.doi.org/10.7453/gahmj.2014.037

4. Minkler M, ed. Community Organizing and Community Building for Health. New Brunswick, NJ, USA: Rutgers University Press, 2002.

5. Morgan E, Swann C. Social capital for health: Issues of definition, measurement and links to health. London: Health Development Agency.

6. Bassuk S, Glass T, Berkman L. Social disengagement and incident cognitive decline in community-dwelling elderly persons. Ann Intern Med 1999;131: 165-73. http://dx. doi.org/10.7326/0003-4819-131-3-199908030-00002

7. Fabrigoule C, Letenneur L, Dartigues J, et al. Social and leisure activities and risk of dementia: a prospective longitudinal study. J Am Geriatr Soc 1995;43:485-90. http://dx.doi.org/10.1111/j.1532-5415.1995.tb06093.x

8. Jenkins R, Meltzer $\mathrm{H}$, Jones PB, et al; Foresight Project on Mental Capital and Wellbeing. Mental health: future challenges. Technical Report. http://eprints.lse.ac.uk/32763

9. Bennett KM. Low level social engagement as a precursor of mortality among people in later life. Age Ageing 2000;31:165-8. http://dx.doi.org/ 10.1093/ageing/31.3.165

10. Holt-Lunstad J, Smith TB, Layton JB. Social relationships and mortality risk: a meta-analytic review. PLoS Med 2010;7:e1000316. http://dx.doi.org/10.1371/journal.pmed.1000316

11. The North Lewisham Health Improvement Programme 2008/14. Evaluation Report (2008/12). http://www.lewishamjsna.org.uk/Reports/North_ Lewisham_Health_Improvement_Programme_Sep13.pdf

12. Sampson RJ, Raudenbush SW, Earls F. Neighborhoods and violent crime: a multilevel study of collective efficacy. Science 1997;227:918-24. http://dx.doi.org/10.1126/science.277.5328.918

13. Skogan W. Fear of crime and neighborhood change. Crime and Justice 1986;8:216-29. http://dx.doi.org/10.1086/449123. http://www.skogan.org/ files/Fear.of.Crime.and.Neighborhood.Change.1986.pdf
14. Sampson RJ, Groves WB. Community structure and crime: testing socialdisorganization theory. Am J Socio/ 1989;94:774-802. http://www.jstor.org/ stable/2780858 https://doi.org/10.1086/229068

15. Clark P, Dawson SL. Jobs and the Urban Poor. Washington DC: Aspen Institute, 1995.

16. Coulter A. Engaging communities for health improvement. A scoping study for the Health Foundation, 2009. http://www.health.org.uk/publication/engaging-communities-health-improvement

17. Fulbright-Anderson K, Auspos P, eds. Community Change: Theories, Practice, and Evidence. Queenstown, MD, USA: Aspen Institute, 45. https://www.aspeninstitute.org/content/uploads/files/content/docs/rcd/COM MUNITYCHANGE-FINAL.PDF

18. Marmot M. Work and other factors influencing coronary health and sickness absence. Work Stress 1994;8:191-201. https://dx.doi.org/10.1080/02678379408259989

19. Daly G. LinkAge Plus: Benefits for older people. Department for Work and Pensions, Research Report No 554, 2009. https://www.gov.uk/government/uploads/system/uploads/attachment_data/file/186776/rrep554.pdf

20. Local Government Association. Benefits of investing in community empowerment. http://www.local.gov.uk/web/guest/past-event-presentations/-/journal_content/56/10180/3581896/ARTICLE

21. Local Government Group. Integrating community engagement and service delivery - pointers to good practice. September 2010. http://www. local.gov.uk/c/document_library/get_file?uuid=6dba73c3-09e2-4e96-869ee9a760fc46ad\&groupld=10180

22. Marmot M. Fair Society, Healthy Lives. Strategic Review of Health Inequalities in England post 2010. The Marmot Review, February 2010, p 139. ISBN 978-0-9564870-0-1. http://www.instituteofhealthequity.org/resources-reports/fair-society-healthy-lives-the-marmot-review

23. Bartley M, ed, on behalf of the ESRC Priority Network on Capability and Resilience, 2003-2007. Capability and resistance: beating the odds. Department of Epidemiology and Public Health Project No RES-337-250001W. www.ucl.ac.uk/capabilityandresilience.

24. Wilkinson RG. The Impact of Inequality: How to Make Sick Societies Healthier. Abington: Routledge, 2005.

25. Fisher B. Community development through health gain and service change - do it now! London J Prim Care 2014;6:154-8. https://doi.org/10.1080/17571472.2014.11494367

26. Fisher B, Chanan G. Social action for health gain: the potential of community development. Br J Gen Pract 2015;65:97-8. http://dx.doi.org/10.3399/bjgp15X683641

27. Nef Consulting. Catalysts for community action and investment: a social return on investment analysis of community development work based on a common outcomes framework. October 2010. http://www.cdf.org.uk/ wp-content/uploads/2011/12/SROI-Report-FINAL1.pdf

28. Reeves D, Blickem C, Vassilev I, et al. The contribution of social networks to the health and self-management of patients with long-term conditions: a longitudinal study. PLoS One 2014;9:e98340. http://dx.doi.org/10.1371/journal.pone.0098340

29. Windle K, Wagland R, Forder J, D'Amico F, Janssen D, Wistow G, for the Personal Social Services Research Unit. The National Evaluation of Partnerships for Older People Projects: Executive Summary. http://www. pssru.ac.uk/pdf/rs053.pdf

30. The National Endowment for Science Technology and the Arts (NESTA). The business case for people powered health. April 2013. http://www. nesta.org.uk/publications/business-case-people-powered-health

31. YMCA. Y-Active Project. http://ymcayactive.org

32. Willow Garden Project. willowgardenproject.org.uk

33. Waugh N. Screen and intervene to prevent diabetes? BMJ 2017;356:i6800. http://dx.doi.org/10.1136/bmj.i6800

34. Dunkley AJ, Bodicoat DH, Greaves CJ, et al. Diabetes prevention in the real world: effectiveness of pragmatic lifestyle interventions for the prevention of type 2 diabetes and of the impact of adherence to guideline recommendations: a systematic review and meta-analysis. Diabetes Care 2014; 37:922-33. http://dx.doi.org/10.2337/dc13-2195

35. Spencer $M$. The doctor who wants to make his town better http://www.bbc.co.uk/news/health-37338995 